\title{
A Corpus-based Stylistic Analysis of Body-Soul and Heaviness- Lightness Metaphors in Kundera's Novel The Unbearable Lightness of Being
}

\author{
Khalid Shakir Hussein (Corresponding author) \\ English Department, College of Arts, Thi-Qar University, Iraq \\ E-mail: khalidshakir74@gmail.com \\ May Ali Abdul Ameer \\ English Department, College of Arts, Thi-Qar University, Iraq
}

\author{
Doi:10.7575/aiac.alls.v.6n.5p.22
}

URL: http://dx.doi.org/10.7575/aiac.alls.v.6n.5p.22

Received: 29/04/2015

Accepted: 11/07/2015

\begin{abstract}
This paper represents an attempt to conduct a corpus-based stylistic analysis of two conceptual metaphors in The Unbearable Lightness of Being, which is a novel written by Milan Kundera. Soul-body and lightness-heaviness metaphors are foregrounded as being central themes all through the novel. The way such metaphors are used in the novel indicates an insightful employment of metaphor as a cognitive tool which empowers language users with a capacity of conceptualizing different experiences. The researcher adopts conceptual metaphor theory to produce a sort of conceptual analysis incorporating Leech's semantic componential analysis within the overall analytic procedure. Different techniques are figured out in relation to the creative ways of manipulating the cognitive level of language, such as conceptual switching, conceptual extension, and conceptual fusion. These creative techniques are carefully used in the novel under investigation with different ranges of metaphorical creativity. Conceptual switching might be simple but very active in deviating from the conventional conceptual system. Conceptual extension marks certain minute elaborations conventional metaphors undergo extending the limits of cognitive conceptualization. As for conceptual fusion, it proves to be interestingly powerful in producing certain aggregations of metaphorical mappings.
\end{abstract}

Keywords: Conceptual Metaphor Theory, Metaphorical Creativity, Metaphorical Mappings, Corpus Stylistics

\section{Introduction}

Studying metaphor has received a huge emphasis by the emergence of a cognitive linguistic approach. This area of investigation underscores the exploration of the way language reflects the conceptual system of its users and the way metaphors, in particular, are stylistically used within specific texts by individual writers.

Metaphor is no more looked at as a characteristic of language alone, rather it is a cognitive mechanism that can reveal a lot about the nature of thought and language (Lakoff and Johnson, 1980:3). Thus, through linking it to thought, metaphor acquires an exceptional significance in widening the horizons of the traditional levels of stylistic analysis. The cognitive or conceptual level is by far a more advanced and dynamic level of analyzing the idiosyncratic features of style than the traditionally analyzed levels of phonology, syntax, morphology, lexicon, and semantics.

This paper represents an attempt to conduct a cognitive stylistic analysis of two basic conceptual metaphors in a relatively modern novel (The Unbearable Lightness of Being) by a controversial novelist (Milan Kundera). This novel, the researcher assumes, is a vivid evidence of the utility of conducting cognitive stylistic analysis on a literary text to figure out the nature of the cognitive deviations that characterize the author's outstanding stylistic traits.

The remaining part of the paper will shed some lights upon the nature of the theories dealing with metaphor as a cognitive phenomenon indicating the specific theory this paper works under. Then, another challenge would be treated carefully regarding the methodology used throughout this paper: a corpus-based analytical method. The special purpose corpus (or database) will be described so that a clear idea will be presented about the procedures followed in its compilation throughout the study. Later on, the researcher will engage in a complete cognitive stylistic analysis of the conceptual metaphors intended in this paper reaching to a stage where highly probable conclusions can be drawn.

\section{Metaphor: Theories}

A great deal of interest has been triggered by various linguists regarding the cognitive nature of metaphor. Though divergent, the approaches investigating metaphor fall into two basic types. Traditional approach of metaphor holds a bunch of theories sharing one basic ground of assumptions. It was traced back to Aristotle to put the oldest known theory of metaphor (Cameron, 1999:9). Aristotle ingeniously suggests a broad but inspirational definition of metaphor: it means simply giving something a name that belongs to another (cited in Esager, 2011:8). Examinations of the 
writings of Aristotle on metaphor, produced in the 4th century B.C., reveals a tendency to divide metaphor on the bases of pairs and restricting its significance to a mere decorative literary device (Cameron, 1999: 10).

As for the alternative approach, it is called the cognitive linguistic approach. This approach also involves a set of theories about the cognitive nature of metaphor. The researcher is interested in one particular cognitive theory called the Conceptual Metaphor Theory. This theory represents a drastic shift in metaphor studies triggered by Lakoff and Johnson's (1980) book Metaphors We Live By. It arose from an urgent need to take into consideration the new findings in psychology of categorization and the prototype theory (ibid.).

However, it might be quite crucial to determine what is meant by cognitive since this term is used in a considerable variation in cognitive psychology, cognitive linguistics, and relevance theory. This paper relies on Kovecses and Szabo's (1996) distinction of traditional approach and cognitive approach to idioms. Their distinction lies in separating between two views: one (traditional) sees that language system and conceptual system are separable. The other (cognitive) view puts things the other way round: language and conceptual systems operate interactively.

\subsection{The Cognitive Linguistic Theory of Conceptual Metaphor}

Conceptual metaphor theory is one particular interesting cognitive theory that produces quite controversial analyses of metaphor as a mental phenomenon. It defines the term 'metaphor' as referring to a mental process of conceptualization that consists in mapping between two domains in the conceptual system: one is called source domain, the other target domain (Reddy, 2003:392). The conceptual relation between the two domains can be represented by this relational form: ( $\mathrm{X}$ is $\mathrm{Y}$ ) where $\mathrm{X}$ is the target and $\mathrm{Y}$ is the source (Sullivan, 2007:69).

However, this conceptual metaphor is realized through a linguistic metaphor. Lakoff (1993: 203) defines the term "metaphorical expression" in a way that puts conceptual and linguistic metaphors in an interesting relationship: "a linguistic expression (a word, a phrase, or sentence) that is the surface realization of such a cross-domain mapping". Therefore, utterances such as (is that the foundation for your theory?) and ( we need to construct a strong argument for that ) (Ibid, 2003: 46) are metaphorical expressions or linguistic metaphors that realize a conceptual metaphor referred to as THEORIES (and ARGUMENTS) ARE BUILDINGS. The way these expressions are written, with capital letters, is part of the notation system Lakoff used functioning as "mnemonics for sets of cross-domain ontological correspondences that characterize each mapping" (Semino, 2003: 1273).

It is conceptual metaphor that holds the researcher's interest. It is well known that any study works within the traditions of cognitive linguistic approach most definitely shows an interest in the conceptual rather than the linguistic level of metaphor analysis. Nevertheless, the fact that metaphor is more than language does not mean that language form is irrelevant to the study of metaphor (Cameron and Low,1999:12). Language is an important source of evidence for embarking a conceptual analysis of metaphors.

The concepts that lie under our thought system are not restricted only to the intellect (Lakoff, 2003: 3). People are normally not totally aware of their conceptual systems due to the automatic way people act in everyday life situations. Language comes then as one way of finding out about the nature of the concepts that lie beneath the surface of the linguistic structures they produce (Cameron, 1999:11-12). Therefore, language functions as a gateway to the conceptual system that characterizes the way people use language.

Consequently, this means that cognitive linguists can derive cognitive structures from linguistic structures. Lakoff (1993: 210) stresses the existence of systematic linguistic correspondences that function as the basis for the existence of a system of conceptual metaphors.

\section{The Concept of Metaphorical Creativity and Cognitive Stylistic Analysis}

Metaphorical creativity was studied by Lakoff and Turner (1989) in their paper More Than Cool Reason. What basically helps in our study is their distinction of metaphor types into conventional and creative (ibid: 22). This classification implies a procedure to identify these two types of metaphors. Orwell (1968:130) puts a semi-procedure to differentiate between the two types:

A newly invented metaphor assists thought by evoking a visual image, while on the other hand a metaphor which is technically 'dead' (e.g. iron resolution) has in effect reverted to being an ordinary word and can generally be used without loss of vividness. But in between these two classes there is a huge dump of worn-out metaphors which have lost all evocative power and are merely used because they save people the trouble of inventing phrases for themselves.

Nevertheless, Orwell's procedure is hard to work out in a corpus of real data. There is no clear cut technical differentiation between what Orwell considers as active or dead or worn-out metaphors. Thus, it is quite crucial to develop a set of explicit criteria that can be used to distinguish between conventional and creative metaphors.

\subsection{Creative Metaphors}

Creativity in stylistic terms used to be described as being equivalent to linguistic deviation (see Leech and Short 2007, Simpson 2004, and Verdonk 2006). This is a deviation from the norms and rules of the language system, a matter that would break the readers' linguistic expectations. The linguistic sense of creativity, within this stylistic framework, lies in a deviational relationship between the readers' linguistic knowledge and the writers' linguistic performance. The latter 
might, for artistic reasons, fail the readers' linguistic expectations that he built up from normal and ordinary everyday life uses of language.

As for creativity within the cognitive linguistic paradigm, it is grounded in a different type of deviational relationship. Cognitively speaking, creative metaphors, for example, are characterized by a knowledge deviation rather than $a$ linguistic deviation. The deviational relationship is cognitive rather than linguistic. It holds between the readers' world knowledge and the writers' artistic world knowledge (Lakoff and Turner, 1989: 60-61).

Metaphors are conventional as long as they trigger a conventional knowledge of the world. Thus, to understand a target domain via a metaphorical comparison to a source domain, one needs a particular knowledge about the source domain (ibid.). For example, the LIFE IS A JOURNEY metaphor depends on the conventional knowledge the people have about the source domain JOURNEY, a knowledge which is technically called schemata. Our knowledge or schemata about journeys would shape our understanding of LIFE. All journeys must have a specific set of components ( taking into consideration Leech's componential analysis) such as: travelers, paths to travel along, places we start traveling from, purposes, destinations, vehicles, etc (ibid: 62-63). All this general knowledge of journeys is used hand in hand with certain mental metaphors to conceptualize life or any other target domain.

Conversely, metaphors are creative if they rely upon a creative knowledge of the world ( a creative schemata), a knowledge that deviates from the readers' expected schematic knowledge of the world (Muller, 2005:56). Thus, the way the readers used to understand a target domain in terms of an expected source domain might be given up for another creative way that suggest a novel conceptualization of the same target domain but in respect of a different unexpected or dissimilar source domain (Gibbs, 1994:7).

\section{Methodology}

This paper utilizes two approaches to analyze and identify the metaphorical creativity of two conceptualizations (Lightness-Heaviness and Soul-Body) in Kundera's novel The Unbearable Lightness of Being: the Topic-Vehicle approach and the Corpus-based approach. Each approach is sketched out below.

\subsection{Topic-Vehicle Approach}

The structure of metaphors is described in terms of two key concepts usually used in any consideration of the constituent components that build up metaphors. The first component is called Topic (sometimes the Tenor) (Cameron, 1999:13). This Topic is closely associated with the target domain. The second component is called Vehicle and corresponds to the source domain (ibid.).

It is noteworthy that Topic and Vehicle within the cognitive context have nothing to do with the implications of the linguistic surface structures. They go beyond such surface structures identifying the underlying conceptual mappings that underlie the structural manifestations of language. Thus the conceptual analysis of the metaphor ARGUMENTS ARE BUILDINGS would produce:

$$
\begin{array}{ll}
\text { TOPIC/ Target } & \text { arguments } \\
\text { VEHICLE/ Source } & \text { buildings }
\end{array}
$$

Topic and Vehicle are taken as conceptual domains underlying lexical items (arguments vs. buildings) (Cameron and Low, 1999: 17). Then, it is inescapable to resort to Leech's (2012) componential semantics so that one can account for metaphor as a relational construct that juxtaposes two conceptual meanings.

This would most definitely relate Leech's componential semantic analysis to cognitive conceptual analysis of metaphor. Adopting such an eclectic approach would involve breaking down the senses of Topics and Vehicles into their minimal semantic distinctive features (see Leech 2012). Consequently, this would help much in finding out the semantic fields of Topics and Vehicles identifying the underlying conceptual content of their domains (Cameron and Low, 1999: 18).

What is more, the relations of contrast and affinity that bring Topic and Vehicle together in one metaphor would be vividly worked out. This entails the fact that the interpretation or the conceptual analysis of a metaphor would involve "the transfer of relations between the semantic field of the Vehicle and that of the Topic" (Kittay, 2003: 225). That is, the mapping as a mental process would be feasible.

Approaching metaphorical conceptualizations in this eclectic way would hopefully empower an interesting type of conceptual analysis of metaphor. Leech (2012: 44-45), for example, gives an illustrative conceptual analysis of a creative metaphor used in an Anglo-Saxon poem. The expression merehengest (sea-steed) is used as a metaphor for ship (ibid.). The researcher will explain Leech's conceptual analysis of the above metaphor using Ungerer and Schmid's (2006) explanatory components of conceptual metaphor. The illustration below pins down the transfer (or mapping) of relations between the semantic fields and features of Topic/ target (ship) and Vehicle/ source (sea-steed) to analyze the conceptualizations involved in the metaphor SHIP IS A SEA-STEED: 


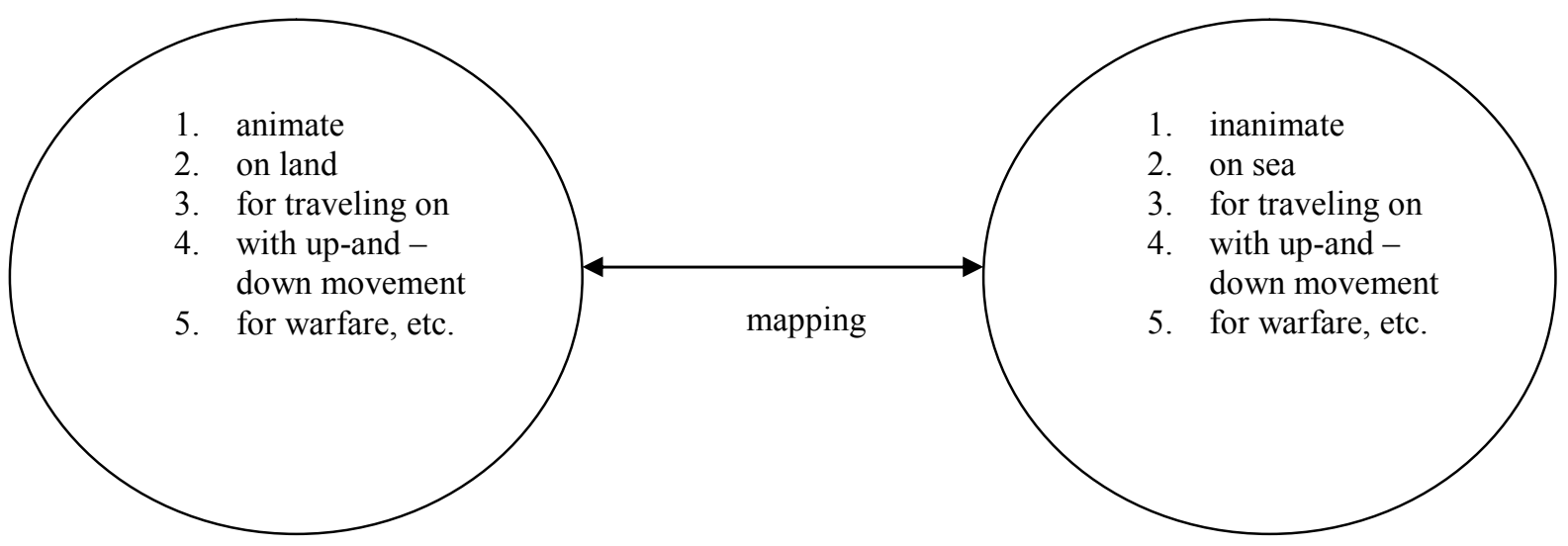

SOURCE CONCEPT

TARGET CONCEPT

Figure 1. Conceptual Analysis of the Metaphor Sea-Steed

Figure (1) above represents a conceptual analysis of metaphor that foregrounds the basic conceptual elements involved in creating a metaphor. Three elements are used: Vehicle, Topic, and the process of mapping. This analysis is enriched by listing the componential meanings of both Vehicle and Topic so that a justification of mapping might be hit.

\subsection{Corpus-based approach to Metaphor}

It is evident that recently corpus-based approaches have established themselves as a major source of different empirical techniques in modern linguistics. Such techniques have been applied to various types of linguistic investigations and research areas. This includes basically all levels of linguistic structure and different aspects of language use (Stefanowitsch, 2006:1).

Nevertheless, the area of conceptual metaphors did not receive much investigations carried out by corpus linguists. Though some research-lines have been set out to explore the nature of metaphor, they are still in line with the context of critical discourse analysis and the goals were mere ideological (Deignan, 1999: 178).

Conducting a corpus-based analysis of metaphor is a quite challenging task. It is not an easy task to identify and retrieve the data one is looking for in a computerized corpus. The difficulty of this task might not be serious in investigating lexical items, fixed expressions, grammatical structures and parts of speech especially if the corpus surveyed was annotated (Stefanowitsch, 2006:1).

All these features are relatively easy to retrieve in a corpus since they are usually linked to particular linguistic forms. Things are radically different with conceptual metaphors. The problem is that conceptual mapping is not restricted to a specific set of linguistic forms (ibid:2). There might be different sets of linguistic forms that correspond to the intended conceptual mapping. Different techniques, however, have been suggested by researchers to extract "linguistic expressions manifesting conceptual mappings ..." (ibid.).

It is beyond the scope of this paper to go through all these techniques and strategies. Thus, the researcher is particularly interested in applying one specific technique that consists in searching for Topic/ target domain vocabulary. Almost always Topic/target domains are sought through a particular computerized corpus. Finding the Topic/target domain would be of much help to figure out the nature of the conceptual mapping that it belongs to. This technique would require the researcher first to select and search for those lexical items referring directly to Topic/target domain concepts. Second, the researcher identifies those occurrences of the topic/target domain which indicate a metaphorical (rather than literal) status. Identifying such occurrences would help in working out the metaphorical mappings occurring with the topic/target domain.

\subsection{WordSmith Tools (Version 5.0)}

The emergence of user-friendly softwares appeared as being one by-product reflection of the revolution set in the field of hardware and software technology in the late 1980s and 1990s (O'keeffe and McCarthy, 2010: 5). The limitations of the computational progress, during the 1970 s, constituted a salient impediment to any serious linguistic effort to exploit computational power in studying large corpora .

WordSmith Tools Version (5.0) represents one good and up-to-date example showing how friendly the programs could be in processing linguistic data. As Scott (2010: 2), the programmer, puts it : "WordSmith Tools is an integrated suite of programs for looking at how words behave in texts." This suite of programs comprises three tools: the WordList tool (lets you see a list of all the words or word-clusters in a text, set out in alphabetical or frequency order); the concordancer, Concord, (gives you a chance to see any word or phrase in context); and Keywords with which you can find the keywords in a text) (ibid.).

The tools are widely used by Oxford University Press in working out some modern dictionaries, by language teachers and students, and particularly by researchers interested in exploring linguistic patterns of different languages. 
The concordancer tool will be extensively used in this study to account for the Topic/target lexical items being used in their various contexts. Below is a preliminary introduction to this tool.

\subsection{Concordances}

No one works on any area in corpus linguistics would proceed without coming across the term concordance. Concordance analysis is probably one of the most popular corpus analytic tools that should be undertaken by any researcher interested in corpus-based studies. There is an incredible heap of definitions offered by corpus linguists for what a concordance refers to, however, the one suggested by Sinclair (1991:32) might touch the core of concordance form and function:

A concordance is a collection of the occurrences of a word-form, each in its own textual environment. In its simplest form it is an index. Each word-form is indexed and a reference is given to the place of occurrence in a text.

Word-form might be simply replaced by lemma- "a set of lexical forms having the same stem and belonging to the same major word class, differing only in inflection and/or spelling" (Francis \& Kucera, 1982:1)- a matter which complicates the searching process since every word-form (singular, plural, gerund, etc.) should be searched independently.

The expected output of a concordance is a list of all the occurrences of a word-form in a particular corpus, together with its context in which it occurs - usually a few words to the left and right of the search word or usually called node. This is why concordance programs are also referred to as KWIC (Key Words In Context) (Scott, 2010: 147).

\subsection{The Analysis Procedure}

The corpus used throughout this paper is a novel compiled via the Internet. The corpus will be analyzed following a procedure of five steps:

1. Authenticity Investigation: it is quite expected that "a corrupt sample" would most definitely produce "a corrupt analysis" (Juola, 2008:247). Consequently, it should be determined that the digital or electronic text version of the novel is a clean one, a task which sounds extremely difficult if not impossible. Since the version selected for this study is machine-readable, the scanning or retyping processes could be a very threatening source of all types of errors. The researcher tried his best to check the authenticity of the electronic corpus making sure that it is highly representative of the paper version of the novel.

2. Transcribing the electronic text corpus into plain text format.

3. Analyzing the corpus via WordSmith Tools (5.0) for concordances after selecting and searching for the lexical items that match directly to the Topic/target domain.

4. Identifying the contextual occurrences in the concordance list that prove metaphorical status.

5. Conducting a componential semantic analysis of the conceptual concepts involved in the metaphorical expressions found in the concordance list.

\section{Corpus Description}

The corpus used for this study is a novel (The Unbearable Lightness of Being ) written by Milan Kundera. The electronic text of the novel is downloaded from the World Wide Web. The text consists of ( 8,347 tokens). The novel is highly respected within the critical communities. It is an international best-seller and winner of the Los Angeles Times Book Award in 1984, The Unbearable Lightness of Being is distinguished as both a critical and popular success (see https://www.nytimes.com/books/98/05/17/specials/kundera-unbearable.html).

The linguistic surface of the novel looks traditional without having any stylistic peculiarities. However, the conceptual structures that lie beneath the linguistic patterns are quite creative and prominent in terms of two basic Topic/ target domains: Weight/ Lightness and Body/ Soul. These two target domains constitute the basic themes that the novel tries to convey through two central conceptual metaphors : one is related to the concepts of HEAVINESS and LIGHTNESS, the other to BODY and SOUL (see http://www.independent.co.uk/arts-entertainment/books/reviews/book-of-a-lifetimethe-unbearable-lightness-of-being-by-milan-kundera-1501286.html ). These two metaphors will be analyzed in the remaining part of this paper as they form two central and controlling motives in the novel.

\section{The Analysis}

The investigation of metaphorical topic/target domains is based on retrieving representative lexical items from the corpus of Kundera's novel using concord lists obtained by WordSmith Tools (version 5.0). The relative frequency of topic/ target domain items will be examined whether they are motivated by metaphorical mappings or not.

\subsection{Heaviness/Lightness Metaphor}

The experience of weight, exemplified by heaviness and lightness, is metaphorically associated with the concepts of HAPPINESS and MISERY. Heaviness versus lightness is a key dichotomy of The Unbearable Lightness of Being. The novelist sets his creative metaphors concerning the concepts of HEAVINESS and LIGHTNESS from the very beginning as one can tell from the title of the novel itself: The Unbearable Lightness of Being.

Kundera himself announces the difference between the conventional metaphorical mapping people used to achieve in regard of HEAVINESS and LIGHTNESS and his deviational conceptual mapping of these two particular concepts: 
When we want to give expression to a dramatic situation in our lives, we tend to use metaphors of heaviness. We say that something has become a great burden to us. We either bear the burden or fail and go down with it, we struggle with it, win or lose. And Sabina-what had come over her? Nothing. She had left a man because she felt like leaving him. Had he persecuted her? Had he tried to take revenge on her? No. Her drama was a drama not of heaviness but of lightness. What fell to her lot was not the burden but the unbearable lightness of being.

( Kundera,1999: 144)

Thus, expressions such as ( something has become a great burden to us, we either bear the burden or fail and go down with it, and we struggle with it, win or lose) give the following conventional conceptual metaphors:

\section{HEAVINESS IS SADDNESS}

\section{LIGHTNESS IS HAPPINESS}

In expressions like ( Her drama was a drama not of heaviness but of lightness. What fell to her lot was not the burden but the unbearable lightness of being ), Kundera breaks up the traditional conceptual mapping all throughout the novel and holds for a completely contrasting conceptual mapping that structures a new creative metaphor represented as follows:

\section{HEAVINESS IS HAPPINESS}

\section{LIGHTNESS IS SADDNESS}

The textual contexts that shape the conceptual reference for these creative metaphors can be observed in the following concord lists produced by WordSmith Tools. The list below centralizes the lexical item (heaviness) as a node matching directly to the topic/ target domain vocabulary.

\section{WordSmith Tools - 23/3/2015}
$\mathrm{N} \quad$ Concordance
Set
Tag
1. ? No. Her drama was a drama not of heaviness but of lightness.
2 lives, we tend to use metaphors of
heaviness. We say that something
3 their splendid lightness. But is
heaviness truly deplorable

The concord list above reveals three occurrences of the lexical item heaviness. But what attracts the researcher's attention is the context of the third occurrence:

". . . then our lives can stand out against it in all their splendid lightness. But is heaviness truly deplorable and lightness splendid?"

The narrator casts doubts about the conventional conceptualizations of the experience of weight. He redefines the whole conventional and prototypical concepts the reader might have about the experience of weight. The narrator invites readers to adopt a new creative conceptual metaphor that conceptualizes the same experience but the other way round:

The heaviest of burdens crushes us, we sink beneath it, it pins us to the ground. But in the love poetry of every age, the woman longs to be weighed down by the man's body. The heaviest of burdens is therefore simultaneously an image of life's most intense fulfillment. The heavier the burden, the closer our lives come to the earth, the more real and truthful they become. Conversely, the absolute absence of a burden causes man to be lighter than air, to soar into the heights, take leave of the earth and his earthly being, and become only half real, his movements as free as they are insignificant. What then shall we choose? Weight or lightness?

$(9$, italics mine)

The excerpt above stretches collocational bonds between heaviness and three positive adjectives highlighting the concept of HEAVINESS as being a positive one: ( . intense fulfillment . . . real . . .truthful . . .). However, two negative adjectives are used to describe the new conceptual context of LIGHTNESS: ( . . half real . . insignificant . . .).

As for the lexical item lightness, it has 17 occurrences throughout the whole corpus. It stands more frequent than heaviness, as the concord list below shows: 
WordSmith Tools $-23 / 3 / 2015$

$\mathrm{N}$ Concordance

1 How she wished she could learn

2 serious, she deprived it of its

longing to betray. The unbearable

aged, and failed to grasp the

its way into the unbearable

wanted to die under the sign of

her, blue, the last. PART FIVE

8 he air, lifted by the infinite

9 the burden but the unbearable

10 then shall we choose? Weight or

11 ? Parmenides responded:

12 against it in all their splendid

13 heaviness truly deplorable and

14 and Sunday, he felt the sweet

15 drama not of heaviness but of

16 on. The only certainty is: the

17 : he was enjoying the sweet
Set

Tag

lightness! She yearned for so

lightness, and it became forced

le lightness of being was that

lightness and amusing insignificance

lightness of being. Though to

lightness. She would be light

Lightness and Weight When

lightness of a world that has

lightness of being. Until that

lightness ? Parmenides posed $\mathrm{t}$

lightness is positive, weight negative.

lightness. But is heaviness truly

lightness splendid? The heaviness

lightness of being rise up to

lightness. What fell to her lot

lightness/ weight opposition is

lightness of being. (Did he feel

As it can be seen, in all the above contexts lightness is used metaphorically to build up the new conceptual metaphor of LIGHTNESS IS SADDNESS. What is unbearable is not HEAVINESS, as it is always expected within the context of the traditional conceptual system, but rather it is LIGHTNESS that weighs down our beings.

The conventional metaphorical mappings for the concepts of HEAVINESS and LIGHTNESS can be represented in the illustration below:

HEAVINESS IS

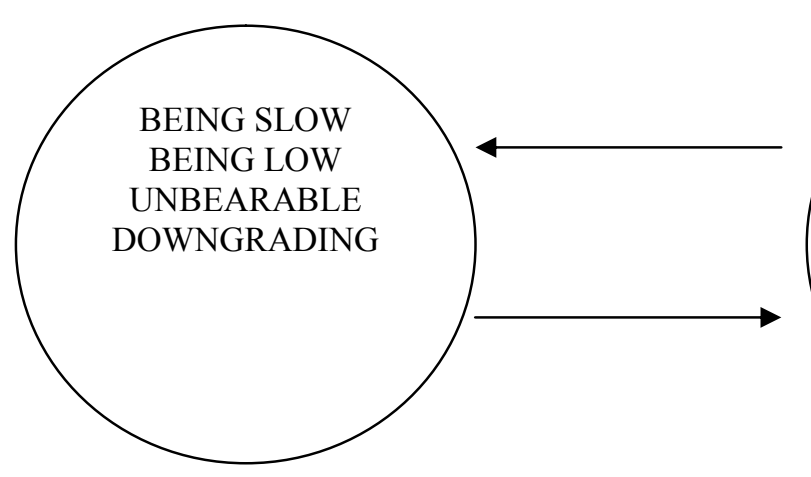

Topic/ Target Domain
LIGHTNESS IS

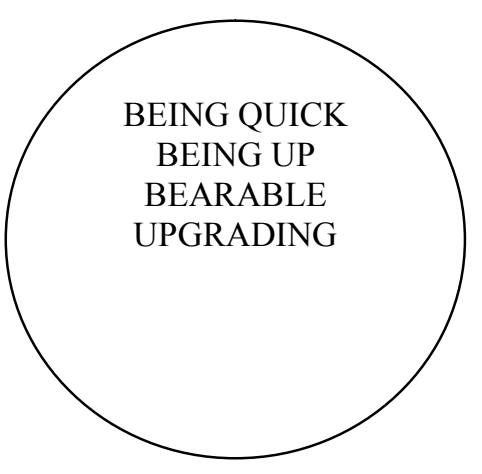

Topic/Target Domain

Figure 2. Traditional Conceptual Analysis of HEAVINESS and LIGHTNESS

The novelist's new conceptualization is grounded in a simple switching of the conceptual mappings usually associated with the topic/target domains. Therefore, he makes all the switches he thinks necessary on the linguistic realizations of this new conceptual metaphor as it can be seen all over the contexts surrounding lightness and heaviness in the concord lists above.

Using Kovecses' (1998) list of metaphorical mappings for the concepts of HAPPINESS and SADDNESS, the same strategy of conceptual switching can be observed in the corpus under investigation, as the illustration below shows: 


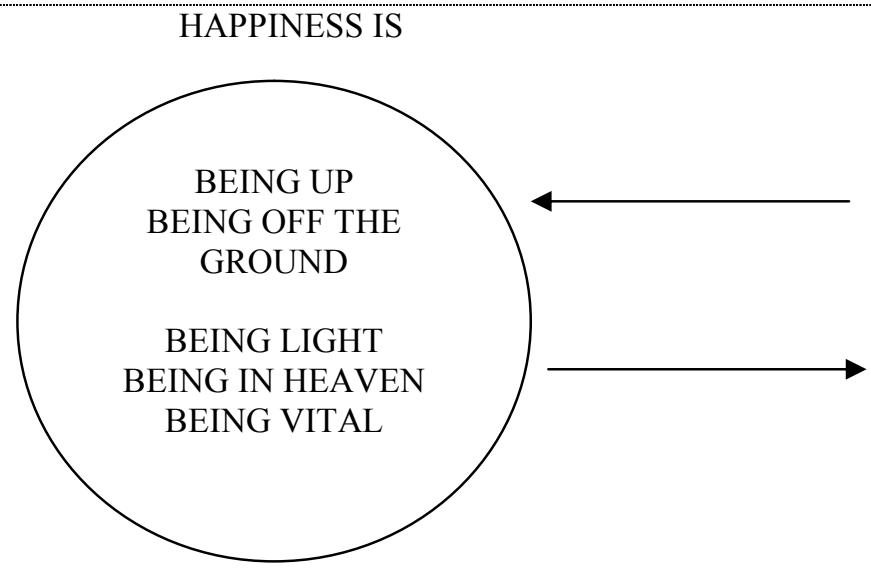

Topic/ Target Domain
SADDNESS IS

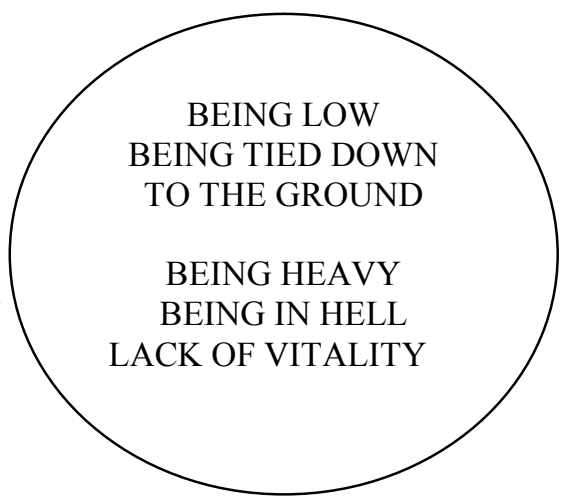

Topic/Target Domain

Figure 3. Traditional Conceptual Analysis of HAPPINESS and SADDNESS

Once again, the novelist relies simply upon an exchange or, as Leech (2012: 45) calls it, "a realigning of the conceptual boundaries" departing from those conceptual mappings usually associated to the topic/target domains of HAPPINESS and SADDNESS. Therefore, he breaks up the conventional and stereotypical bonds of the everyday life conceptual system to create a new metaphorical mapping that suits his artistic goals.

\subsection{Body/Soul Metaphor}

Beside those of HEAVINESS and LIGHTNESS, the concepts of BODY and SOUL hold a central thematic position throughout the corpus explored in this study. The conventional conceptualizations of these two concepts have been described by Lakoff and Johnson (1980, 1999), Johnson (1987), and Kövecses (2010). The conceptualizations they describe are given as:

\section{BODY IS A CONTAINER}

SOUL IS AN OBJECT

However, going through the concord lists of the direct lexical items, body and soul, that match the topic/target domains all over the corpus of this study suggests two new conceptualizations which can be represented as:

\section{BODY IS A SHIP}

\section{SOUL IS A MARINER}

Below is a sample of the concord list produced by WordSmith Tools for the topic/target domain of the lexical item body (the whole list is to be found in the Appendix):

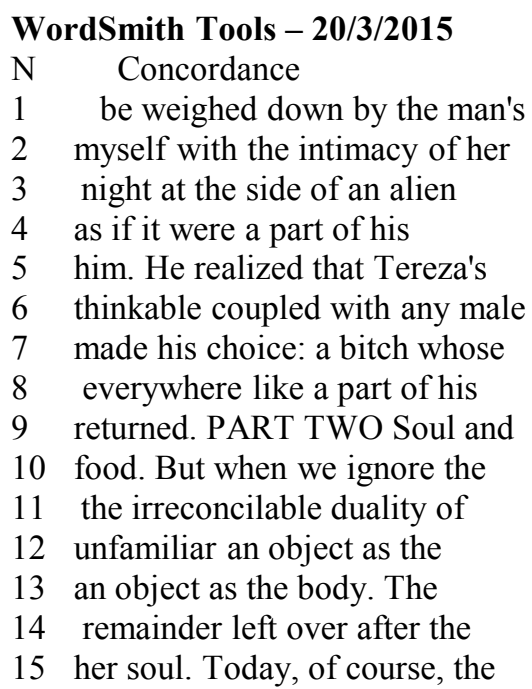

$$
\text { Set Tag }
$$

body. The heaviest of burdens

body. And all at once he fancies

body was distasteful to him,

body. Once, when he had just

body was perfectly thinkable

body, and the thought put him

body seemed reminiscent of the

body meant that Tereza went off

Body It would be senseless

body, we are more easily victims

body and soul, that fundament

body. The body was a cage, an

body was a cage, and inside it

body had been accounted for,

body is no longer unfamiliar:

There are 133 different occurrences of the lexical item body throughout the whole database of the corpus. Different contextual occurrences of body in the concord list above appear to conceptualize BODY as being A SHIP rather than simply A CONTAINER. 
Each time she succeeded was a time of intoxication: her soul would rise to the surface of her body like a crew charging up from the bowels of a ship, spreading out over the deck, waving at the sky and singing in jubilation. (51)

She was ready to dismiss the crew of her soul from the deck of her body; (71)

it opened the door of his body and allowed his soul to step out into the world to make friends (109)

The soul trembled in her body, her naked, spurned body. (185)

her soul would take courage and rise to the surface of her body, and she would burst out crying. (185)

He would not have understood Tereza when she stood before the mirror as a young girl and tried to see her soul through her body. (345)

Nevertheless, one can tell that Kundera's new conceptual metaphor (BODY IS A SHIP) is an extension of the already existing one (BODY IS A CONTAINER) since a ship is after all a type of containers. The illustration below shows a conceptual analysis of the mapping that holds between the topic/target domain (BODY) and the vehicle/source domain (SHIP):

BODY IS $\quad$ SHIP IS

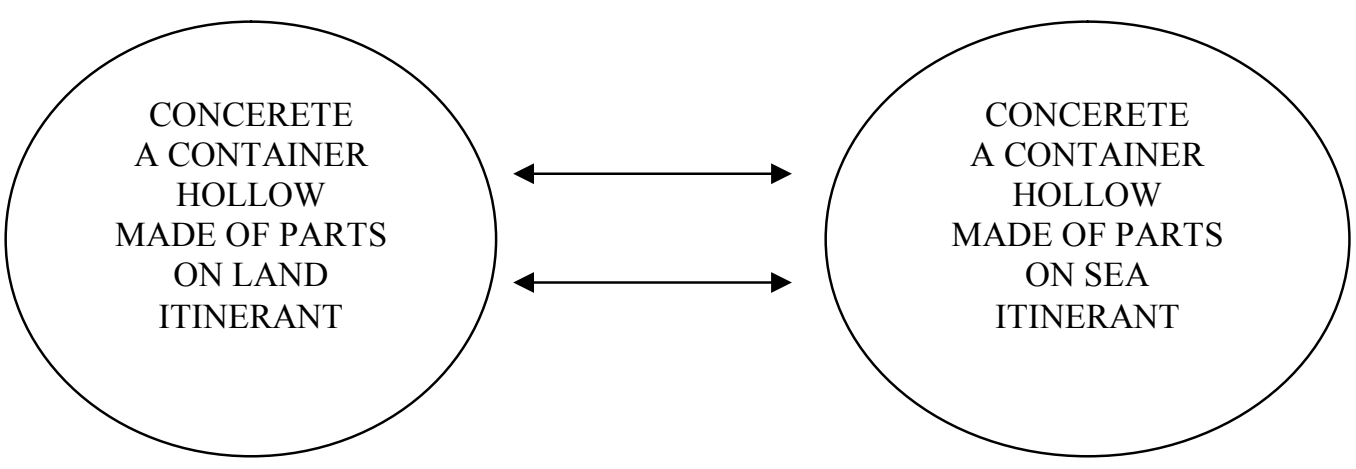

Topic/Target Domain

Vehicle/ Source Domain

Figure 4. Conceptual Analysis of the Metaphorical Mapping between BODY and SHIP

As for the lexical item soul, below is a sample of its concord list that reveals the contextual occurrences of the lexical item as it occurs (for 57 times) all over the corpus (the whole list is to be found in the Appendix):

\section{WordSmith Tools $-23 / 3 / 2015$}

\begin{tabular}{|c|c|c|c|}
\hline & Concordance & & Tag \\
\hline & worst ordinary of bodies (as the & so & had regarded it until the \\
\hline & ne light of the incredible, the & so & for the first time saw the \\
\hline & npletely naked. When her & soul & naked body in the \\
\hline & most extraordinary body. The & soul & could $\mathrm{r}$ \\
\hline & The & sot & tren \\
\hline & enlarged end of a sewer 1 & sou & had \\
\hline & r hody on which & so & , to ta \\
\hline & res & sou & g tha \\
\hline & and she realized that she (her & so & olved \\
\hline 10 & on with Tomas only as a & sou & and ser \\
\hline 11 & & sou & $m$ \\
\hline & & sou & hen $\mathrm{h}$ \\
\hline 3 & & & at the \\
\hline 4 & her & sol & approval would have to \\
\hline & assion and sinks deep into her & so & He leaps out of the win \\
\hline
\end{tabular}

As it can be observed from the concordances of body and soul, the occurrences of these two lexical items are inseparable. Thus, the same linguistic expressions quoted from the corpus for the lexical item body above can be checked again to verify the metaphorical conceptualizations of SOUL. The concept of soul being contained within the body is probably quite common and universal. Nevertheless, Kundera's conceptual metaphor of (SOULS IS A MARINER) is another extension of a conventional metaphor used to structure the ordinary conceptual system. This conventional metaphor is:

SOUL IS AN OBJECT

Conceptualizing soul as being an object is a metaphorical technique called reification by which an abstract concept can be embodied through holding conceptual mappings with some other concrete concept (see Goschler, J. 2005). Thus, 
Kundera's new conceptual metaphor (SOUL IS A MARINER) arises from two metaphorical entailments (see Lakoff and Johnson, 2003:139-141): the first is SOUL IS AN OBJECT, but what kind of an object is SOUL? This question is addressed by another extended conceptual metaphor that reads SOUL IS A HUMAN BEING. Kundera extends the metaphorical entailment even further questioning the particular type of human being a soul might look like: SOUL IS A MARINER.

The following conceptual analysis might give an evident illustration of the reification technique used to conceptualize SOUL as a topic/target domain through conceptual mappings with the vehicle/source domain of A MARINER.

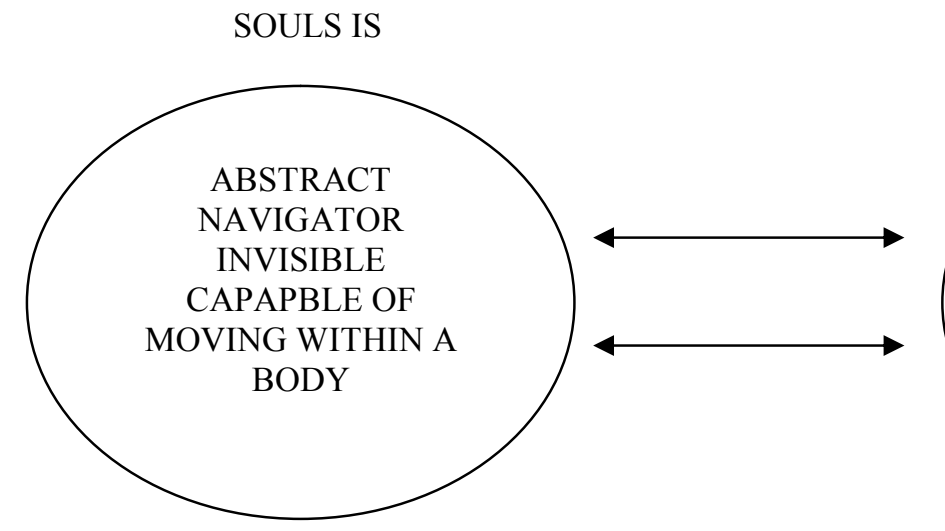

Topic/Target Domain
MARINER IS

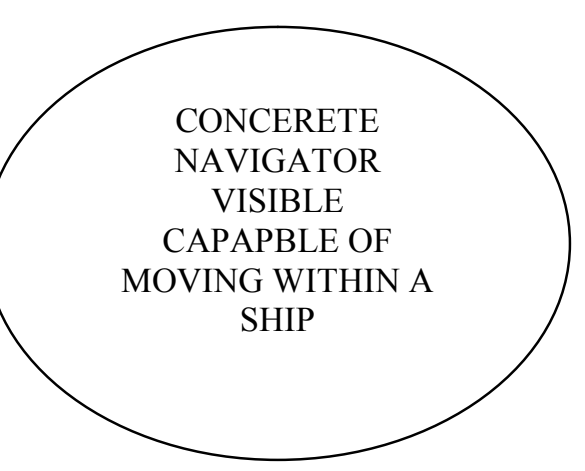

Vehicle/ Source Domain

Figure 5. Conceptual Analysis of the Metaphorical Mapping between SOUL and MARINER

Putting things together, both conceptualizations of BODY and SOUL might be expressed in a mathematical proportional formula:

SOUL / BODY = MARINER/ SHIP

The formula above fuses two simple conceptual metaphors into one complex metaphor with many entailments that can be formulated as:

SOUL IN A BODY IS A MARINER IN A SHIP

This complex conceptual metaphor is brought out by a technique Leech (2012: 43) calls conceptual fusion. It is an outcome of a complex fusion of several metaphorical entailments such as:

BODY IS A CONTAINER

BODY IS A SHIP

SOUL IS AN OBJECT

SOUL IS A HUMAN BEING

SOUL IS A MARINER

The illustration below might be helpful in realizing the conceptual fusion included in the complex conceptual metaphor SOUL IN A BODY IS A MARINER IN A SHIP.

Conceptual Fusion

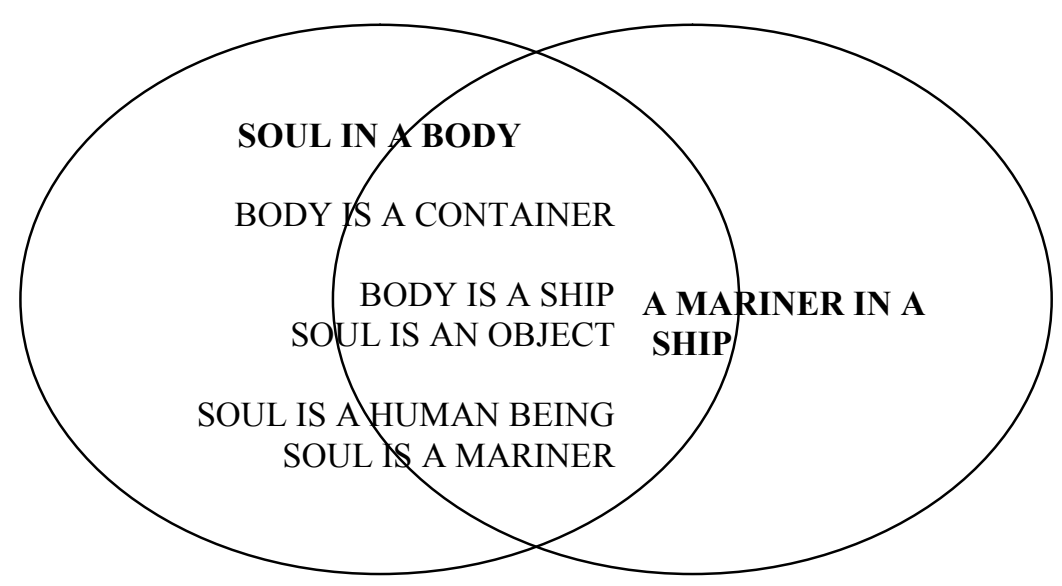

Figure 6. Conceptual Fusion Analysis of the Metaphor SOUL IN A BODY IS A MARINER IN A SHIP

The overlapping area in the conceptual fields is quite evident in figure (6) above. Such overlapping is only feasible because of the notion of conceptual fusion that permits a sort of interaction between conceptual domains of different 
mappings. The result of this conceptual aggregation is a new complex metaphor conceptualizing an experience distinct from its component conceptual domains.

\section{Conclusions}

In this paper, the researcher has tried to show how a corpus-based analysis of key conceptual metaphors in a computerized literary text can provide certain insights about language as a conceptual system. The findings can be summarized in the following points:

1. analyzing the cognitive level of literary language can tell researchers a lot about the writers' conceptual creativity and their aesthetic experience. Therefore, a creative novelist like Kundera has actually created new and extended metaphorical mappings that bring dissimilar domains in one conceptual basket. Literary texts like The Unbearable Lightness of Being provide new ways of structuring artistic experience by adding new conceptualizations of everyday life realities.

2. the conceptual analyses conducted throughout this paper demonstrate the usefulness of corpus-based approach for giving a stylistic description of the cognitive linguistic level in a literary text. A corpus-based approach makes it quite possible to study a large corpus $-8,347$ tokens- having enough information about the frequency and use of linguistic metaphors which is otherwise time consuming and difficult to access. Throughout this paper, concord lists proved useful and straightforward to make a statement about the metaphorical use of a specific topic/target lexical item or node. Such lists are a great help in identifying whether a stretch of language (a lexical item) in a particular context is metaphoric or not.

3. the way new and creative metaphors are structured in the corpus explored adds another dimension to metaphorical innovation in literature. This type of innovation is based on a sort of cognitive deviation that triggers the creation of conceptual metaphors lying outside the conventional system of concepts and thought. Therefore, the conceptual analyses conducted on Kunder's novel The Unbearable Lightness of Being suggest two basic techniques of metaphorical creativity:

a. Extending the already existing conventional metaphors so that the new ones might be viewed as extensions or special cases of stable, conventional conceptual metaphors used in everyday thought and language. Kundera's metaphoric innovations are by no means consisting only in the totally new creation of metaphorical thought but rather in a process of extending the already existing forms of metaphoric thought to form new combinations and aggregations of old metaphorical mappings.

b. Breaking through the conceptual bonds that lie beneath linguistic structures and realigning the boundaries of the conventional system of concepts. This technique might be called conceptual fusion where two conventional metaphors are conceptually mapped into each other fusing into one new complex metaphor.

After all, it is literature that dares most to create new conceptual metaphors and mappings creating new understandings and even new realities. And language is still the basic medium through which new conceptual metaphors are created and old ones are redefined.

\section{References}

Deignan, A. (1999). Corpus-based research into metaphor. In Cameron, L. and Graham, L. (eds), Researching and Applying Metaphor. Cambridge: Cambridge University Press, 177-199.

Esager, M. (2011). Fire and water - a comparative analysis of conceptual metaphors in English and Danish news articles about the credit crisis 2008.

Francis, W. \& Kucera, H. (1982). Frequency Analysis of English Usage: Lexicon and grammar. Boston: Houghton Mifflin.

Gibbs, R., (1994). The Poetics of Mind: Figurative Thought, Language and Understanding. New York: Cambridge University Press.

Goschler, J. (2005). Embodiment and body metaphors. Metaphoric, 9(23), 33-52.

Juola, P., (2008). Authorship Attribution: Foundations and Trends. Boston-Delft: now Publishers.

Kovecses, Z., and Szabo, P. (1996). Idioms: a view from cognitive semantics. Applied Linguistics, 17(3), 326355.

, (2010). Metaphor: A Practical Introduction. Oxford: Oxford University Press.

Kundera, M. (1999). The Unbearable Lightness of Being. London: Penguin Books.

Lakoff, G. (1993). The contemporary theory of metaphor". In: Ortony, A. (ed.), Metaphor and Thought, $2^{\text {nd }}$ ed., Cambridge : Cambridge University Press , 202-251.

Chicago.

, M. T. (1989). More Than Cool Reason: A Field Guide to Poetic Metaphor. Chicago University Press, 

, and Mark, J. (2003). Metaphors We Live By, 5th ed., Chicago and London: Chicago University Press. Thought. New York: Basic Books. (1999). Philosophy in the Flesh: The Embodied Mind and its Challenge to Western

Leech, G. \& Short, M. (2007). Style in Fiction. London and New York: Longman. , (2012). Semantics. London: Penguin Books.

Mark, J. (1987). The Body in the Mind: The Bodily Basis of Meaning, Imagination, and Reason. Chicago; London: Chicago University Press.

Muller, R., (2005). Creative metaphors in political discourse. Metaphoric, 9(23), 53-73.

O'keeffe, A., and McCarthy, M. (2010). The Routledge Handbook of Corpus Linguistics. London and New York: Routledge.

Orwell, G. (1968). Politics and the English language. Collected Essays, $2^{\text {nd }}$ ed., London: Secker and Warburg.

Reddy, J. (2003). The conduit metaphor: a case of frame conflict in our language about language. In Ortony, A. (Ed.), Metaphor and Thought. Cambridge University Press, Cambridge, pp. 284-324.

Scott, M. (2010). What can corpus software do?. In O'keefe, A. \& McCarthy, M. (eds.). The Routledge Handbook of Corpus Linguistics. London and New York: Routledge Books.

Simpson, P. (2005) Stylistics. London and New York: Routledge.

Sinclair, J. (1991). Corpus, Concordance, Collocation. Oxford: Oxford University Press.

Stefanowitsch, A. (2006). Corpus-Based Approaches to Metaphor and Metonymy. Berlin: Mouton de Gruyter. Ungerer F., and Schmid, H. (2006). An Introduction to Cognitive Linguistics. London: Pearson/ Longman. Verdonk, P. (2006). Stylistics. Oxford: Oxford University Press. 
WordSmith Tools -- 20/3/2015

Concordance Set Tag Word \# Sent. \# Sent. Pos. o be weighed down by the man's body. The heaviest of burdens mself with the intimacy of her body. And all at once he fanc night at the side of an alien body was distasteful to him, ly as if it were a part of his body. Once, when he had just him. He realized that Tereza's body was perfectly thinkable hinkable coupled with any male body, and the thought put him made his choice: a bitch whose body seemed reminiscent of th everywhere like a part of his body meant that Tereza went o returned. PART TWO Soul and Body 1 It would be senseless $\mathrm{t}$ food. But when we ignore the body, we are more easily vict the irreconcilable duality of body and soul, that fundament $\mathrm{d}$ unfa-miliar an object as the body. The body was a cage, an iar an object as the body. The body was a cage, and inside t remainder left over after the body had been accounted for, he soul. Today, of course, the body is no longer unfamiliar: of a hose sticking out of the body to take oxygen to the lu ent panel regis-tering all the body mechanisms: digestion, $\mathrm{s}$ arned to give each part of the body a name, the body has giv $\mathrm{h}$ part of the body a name, the body has given him less troub in action. The old duality of body and soul has become shro omach rumble, and the unity of body and soul, that lyrical i ied to see herself through her body. That is why, from girlh at the instrument panel of her body mechanisms; she thought uld rise to the surface of her body like a crew charging up elf to the idea that the human body pisses and farts, she sa ng to express the value of her body in terms of the modesty ther. It was a longing to be a body unlike other bodies, to $\mathrm{s}$ in the hotel restaurant, her body sagged under the weight ul rushed up to the deck other body.) Then she walked him to not to abandon the deck of her body for a moment on this mos ictions, banish the duality of body and soul, banish perhaps nt by her injunction was: Your body is just like all other $b$ he had come to him to make her body unique, irreplaceable. B o distinction between Tereza's body and the other bodies. He her soul from the deck of her body; ready to descend to a p his mistresses! Maybe then her body would again become the $\mathrm{f}$

Appendix (A)

Concord List of Body

Para. \# Para. Pos.

$538 \quad 24$

3103

3410

4325

4333

$6125 \quad 369$

$7379 \quad 455$

$9446 \quad 585$

9561593

$9622 \quad 597$

$9667 \quad 599$

9669600

9694600

$9706 \quad 601$

$9736 \quad 601$

$9754 \quad 602$

$9772 \quad 603$

$9776 \quad 603$

$9805 \quad 605$

$9843 \quad 606$

$9865 \quad 607$

$9932 \quad 61$

$10039 \quad 615$

$10661 \quad 650$

$10804 \quad 658$

$10998 \quad 667$

$11065 \quad 670$

$12058 \quad 734$

12639758

13092788

$13781 \quad 827$

$14092 \quad 845$

$14125 \quad 846$

1464388

$15219 \quad 913$ $100 \%$

$54 \%$

$100 \% \quad 0$

$26 \% \quad 0$

$61 \% \quad 0$

$42 \%$

$70 \%$

$23 \% \quad 0$

$50 \% \quad 0$

$74 \% \quad 0$

$100 \% \quad 0$

$9 \%$

$80 \%$

$14 \% \quad 0$

$86 \%$

$68 \%$

$59 \%$

$77 \% \quad 0$

$24 \%$

$61 \%$

$100 \% \quad 0$

$48 \% \quad 0$

$45 \%$

$71 \%$

$79 \%$

$30 \% \quad 0$

$36 \%$

$100 \% \quad 0$

$72 \% \quad 0$

$79 \%$

$28 \%$

$83 \% \quad 0$

$89 \%$

$36 \%$

$33 \%$
Head. \# Head. Pos.

$00 \% \quad 0 \quad 1 \%$

Sect. \# Sect. Pos.

File

$\%$
$4 \%$

$4 \%$

$5 \%$

$5 \%$

$7 \%$

$9 \%$

$11 \%$

$11 \%$

$11 \%$

$11 \%$

$11 \%$

$11 \%$

$11 \%$

$11 \%$

$11 \%$

$11 \%$

$11 \%$

$12 \%$

$12 \%$

$12 \%$

$12 \%$

$12 \%$

$13 \%$

$13 \%$

$13 \%$

$13 \%$

$14 \%$

$15 \%$

$15 \%$

$16 \%$

$17 \%$

$17 \%$

$17 \%$

$18 \%$

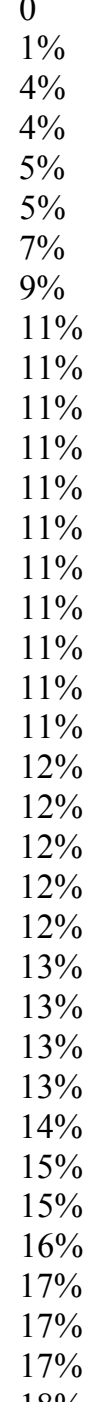

$18 \%$ 
and only among all others. Her body would become his second, ottle of wine. Tereza felt her body going weak; she was sudd

s nothing wrong with the naked body, the woman said with mat a terrific sense of the female body you have. You know what ak, even if he has an athletic body like Dubcek's. The very led the smells of each other's body. True, he would rather $h$ ary; it opened the door of his body and allowed his soul to es. The pleasure suffusing his body called for dark-ness. Th he felt pleasure suffusing his body, Franz himself disintegr e windows to the soul. Franz's body, which thrashed about on $\mathrm{h}$ closed eyes, was therefore a body without a soul. It was 1 she would never again see his body moving desperately over he had closed them on Sabina's body in fifteen European hote in America. PART FOUR Soul and Body 1 When Tereza came home, nt of the mirror observing her body, trying to peer through the blissful hope of using her body as a poster for her soul ve to be if it reflect-ed that body, that rack for four pouc as nothing monstrous about her body. She had no pouches hang he been able to design her own body, she would have chosen $\mathrm{i}$ $\mathrm{s}$ ? And if various parts of her body began to grow and shrink $\mathrm{t}$ at what was happening to her body. Then what was the relat ionship between Tereza and her body? Had her body the right

$\mathrm{n}$ Tereza and her body? Had her body the right to call itself ore the mirror, staring at her body as if it were alien to $h$ $\mathrm{d}$ the power to become the only body in Tomas's life. It had enly she longed to dismiss her body as one dismisses a serva as only as a soul and send her body into the world to behave ehave with male bodies. If her body had failed to become the had failed to become the only body for Tomas, and thereby 1 esistible desire to expose her body (that alien body she wan to expose her body (that alien body she want-ed to expel int $t$ about the idea of going. Her body was so weak that she cou nd burst into tears. Her whole body racked with sobs, she em infidelity. She would push her body up to the border, let it ngineer's hand referred to her body, and she realized that $s$ not at all involved, only her body, her body alone. The bod 1 involved, only her body, her body alone. The body that had her body, her body alone. The body that had betrayed her an d not comply. She had sent her body out into the world, and e soul so excited was that the body was acting against its $w$ $\mathrm{s}$ acting against its will; the body was betraying it, and th

\begin{tabular}{|c|c|c|c|c|c|c|}
\hline 15231 & 914 & $25 \%$ & 0 & $18 \%$ & 0 & $18 \%$ \\
\hline 15908 & 954 & $45 \%$ & 0 & $19 \%$ & 0 & $19 \%$ \\
\hline 17180 & 1023 & $57 \%$ & 0 & $20 \%$ & 0 & $20 \%$ \\
\hline 17266 & 1030 & $87 \%$ & 0 & $20 \%$ & 0 & $20 \%$ \\
\hline 18128 & 1098 & $89 \%$ & 0 & $21 \%$ & 0 & $21 \%$ \\
\hline 20406 & 1250 & $100 \%$ & 0 & $24 \%$ & 0 & $24 \%$ \\
\hline 23243 & 1402 & $66 \%$ & 0 & $27 \%$ & 0 & $27 \%$ \\
\hline 23885 & 1439 & $67 \%$ & 0 & $28 \%$ & 0 & $28 \%$ \\
\hline 23932 & 1442 & $44 \%$ & 0 & $28 \%$ & 0 & $28 \%$ \\
\hline 30363 & 1854 & $15 \%$ & 0 & $36 \%$ & 0 & $36 \%$ \\
\hline 30377 & 1854 & $85 \%$ & 0 & $36 \%$ & 0 & $36 \%$ \\
\hline 30455 & 1859 & $28 \%$ & 0 & $36 \%$ & 0 & $36 \%$ \\
\hline 33855 & 2093 & $62 \%$ & 0 & $40 \%$ & 0 & $40 \%$ \\
\hline 33868 & 2094 & $30 \%$ & 0 & $40 \%$ & 0 & $40 \%$ \\
\hline 35783 & 2194 & $50 \%$ & 0 & $42 \%$ & 0 & $42 \%$ \\
\hline 35809 & 2195 & $68 \%$ & 0 & $42 \%$ & 0 & $42 \%$ \\
\hline 35830 & 2196 & $76 \%$ & 0 & $42 \%$ & 0 & $42 \%$ \\
\hline 35974 & 2206 & $100 \%$ & 0 & $42 \%$ & 0 & $42 \%$ \\
\hline 36043 & 2210 & $26 \%$ & 0 & $42 \%$ & 0 & $42 \%$ \\
\hline 36129 & 2214 & $27 \%$ & 0 & $42 \%$ & 0 & $42 \%$ \\
\hline 36180 & 2216 & $100 \%$ & 0 & $42 \%$ & 0 & $42 \%$ \\
\hline 36190 & 2217 & $100 \%$ & 0 & $42 \%$ & 0 & $42 \%$ \\
\hline 36193 & 2218 & $40 \%$ & 0 & $42 \%$ & 0 & $42 \%$ \\
\hline 36302 & 2227 & $39 \%$ & 0 & $43 \%$ & 0 & $43 \%$ \\
\hline 36333 & 2229 & $77 \%$ & 0 & $43 \%$ & 0 & $43 \%$ \\
\hline 36366 & 2232 & $21 \%$ & 0 & $43 \%$ & 0 & $43 \%$ \\
\hline 36384 & 2232 & $67 \%$ & 0 & $43 \%$ & 0 & $43 \%$ \\
\hline 36400 & 2233 & $12 \%$ & 0 & $43 \%$ & 0 & $43 \%$ \\
\hline 36407 & 2233 & $33 \%$ & 0 & $43 \%$ & 0 & $43 \%$ \\
\hline 37172 & 2278 & $40 \%$ & 0 & $44 \%$ & 0 & $44 \%$ \\
\hline 37175 & 2278 & $52 \%$ & 0 & $44 \%$ & 0 & $44 \%$ \\
\hline 38309 & 2385 & $20 \%$ & 0 & $45 \%$ & 0 & $45 \%$ \\
\hline 39350 & 2461 & $7 \%$ & 0 & $46 \%$ & 0 & $46 \%$ \\
\hline 39738 & 2490 & $12 \%$ & 0 & $47 \%$ & 0 & $47 \%$ \\
\hline 40343 & 2530 & $33 \%$ & 0 & $47 \%$ & 0 & $47 \%$ \\
\hline 40358 & 2530 & $89 \%$ & 0 & $47 \%$ & 0 & $47 \%$ \\
\hline 40360 & 2530 & $96 \%$ & 0 & $47 \%$ & 0 & $47 \%$ \\
\hline 40363 & 2531 & $16 \%$ & 0 & $47 \%$ & 0 & $47 \%$ \\
\hline 40403 & 2534 & $33 \%$ & 0 & $47 \%$ & 0 & $47 \%$ \\
\hline 40550 & 2543 & $43 \%$ & 0 & $48 \%$ & 0 & $48 \%$ \\
\hline 40557 & 2543 & $68 \%$ & 0 & $48 \%$ & 0 & $48 \%$ \\
\hline
\end{tabular}


d. When her soul saw her naked body in the arms of a strange oul for the first time saw the body as something other than he first time it looked on the body with fascination: all th body with fascination: all the body's matchless, inimitable, his was the most extraordinary body. The soul could not tear ot tear its eyes away from the body's birthmark, the round b y seal it had imprinted on the body, and now a stranger's pe that she would never allow her body, on which her soul had 1 e pace of his movements on her body. Tereza could feel orgas lingered all the longer in her body, flowing through her vei ct does all he can to make the body forget how paltry it is, , to become only and utterly a body, the body her mother use e only and utterly a body, the body her mother used to say w more miserable than her naked body perched on the enlarged it had retreated deep into the body again, to the farthest $\mathrm{g}$ room. The soul trembled in her body, her naked, spurned body $\mathrm{n}$ her body, her naked, spurned body. She still felt on her a and rise to the surface of her body, and she would burst out er neck, and pressed it to her body with her left hand. With come out of the toilet and her body was standing in the ante ed, in the mirror) was her own body: her pubic triangle and She did not desire her lover's body. She desired her own bod er's body. She desired her own body, newly discovered, intim rably exciting. Looking at her body speckled with droplets o by folding his legs under his body, as he had learned to do e photograph showing her naked body embracing the engineer. slitting open the outstretched body of the world with his sc en, focused and observant, his body ever so slightly arched he used to open the prostrate body of the world. Before he charming acting student whose body had been tanned on Yugos ly in his arms and feeling her body tremble, he thought he c ost likely lain dormant in his body until then suddenly blos try penetrated the soul to the body, shat-tering the latter. until the last moment that the body would be cremated at hal $\mathrm{m}$, putting her arms around his body from the side. What abou ings he'd put himself through! Body, hands, face, to make su he have been excited when his body was debili-tated by a ga er who once formed part of our body. Tomas's other part is $t$ e camp. He hit the target. His body, which would never again lectrified wire and hurled his body at it, the fence was lik An explosion rang out, and his body, ripped to pieces, went

\begin{tabular}{|c|c|c|c|c|c|c|}
\hline 40584 & 2545 & $25 \%$ & 0 & $48 \%$ & 0 & $48 \%$ \\
\hline 40623 & 2546 & $36 \%$ & 0 & $48 \%$ & 0 & $48 \%$ \\
\hline 40637 & 2546 & $67 \%$ & 0 & $48 \%$ & 0 & $48 \%$ \\
\hline 40642 & 2546 & $78 \%$ & 0 & $48 \%$ & 0 & $48 \%$ \\
\hline 40674 & 2547 & $100 \%$ & 0 & $48 \%$ & 0 & $48 \%$ \\
\hline 40685 & 2548 & $57 \%$ & 0 & $48 \%$ & 0 & $48 \%$ \\
\hline 40711 & 2549 & $62 \%$ & 0 & $48 \%$ & 0 & $48 \%$ \\
\hline 40736 & 2550 & $39 \%$ & 0 & $48 \%$ & 0 & $48 \%$ \\
\hline 40803 & 2553 & $100 \%$ & 0 & $48 \%$ & 0 & $48 \%$ \\
\hline 40834 & 2555 & $69 \%$ & 0 & $48 \%$ & 0 & $48 \%$ \\
\hline 40884 & 2558 & $29 \%$ & 0 & $48 \%$ & 0 & $48 \%$ \\
\hline 41056 & 2563 & $70 \%$ & 0 & $48 \%$ & 0 & $48 \%$ \\
\hline 41058 & 2563 & $74 \%$ & 0 & $48 \%$ & 0 & $48 \%$ \\
\hline 41097 & 2565 & $53 \%$ & 0 & $48 \%$ & 0 & $48 \%$ \\
\hline 41124 & 2566 & $59 \%$ & 0 & $48 \%$ & 0 & $48 \%$ \\
\hline 41157 & 2568 & $64 \%$ & 0 & $48 \%$ & 0 & $48 \%$ \\
\hline 41161 & 2568 & $100 \%$ & 0 & $48 \%$ & 0 & $48 \%$ \\
\hline 41222 & 2571 & $80 \%$ & 0 & $48 \%$ & 0 & $48 \%$ \\
\hline 41635 & 2602 & $85 \%$ & 0 & $49 \%$ & 0 & $49 \%$ \\
\hline 41859 & 2620 & $68 \%$ & 0 & $49 \%$ & 0 & $49 \%$ \\
\hline 42269 & 2644 & $62 \%$ & 0 & $50 \%$ & 0 & $50 \%$ \\
\hline 42351 & 2649 & $100 \%$ & 0 & $50 \%$ & 0 & $50 \%$ \\
\hline 42356 & 2650 & $38 \%$ & 0 & $50 \%$ & 0 & $50 \%$ \\
\hline 42370 & 2651 & $25 \%$ & 0 & $50 \%$ & 0 & $50 \%$ \\
\hline 42751 & 2683 & $63 \%$ & 0 & $50 \%$ & 0 & $50 \%$ \\
\hline 44492 & 2816 & $81 \%$ & 0 & $52 \%$ & 0 & $52 \%$ \\
\hline 52977 & 3335 & $68 \%$ & 0 & $62 \%$ & 0 & $62 \%$ \\
\hline 55373 & 3471 & $67 \%$ & 0 & $65 \%$ & 0 & $65 \%$ \\
\hline 55603 & 3488 & $88 \%$ & 0 & $65 \%$ & 0 & $65 \%$ \\
\hline 60608 & 3830 & $26 \%$ & 0 & $71 \%$ & 0 & $71 \%$ \\
\hline 61461 & 3894 & $55 \%$ & 0 & $72 \%$ & 0 & $72 \%$ \\
\hline 61748 & 3912 & $63 \%$ & 0 & $72 \%$ & 0 & $72 \%$ \\
\hline 61809 & 3914 & $88 \%$ & 0 & $73 \%$ & 0 & $73 \%$ \\
\hline 61991 & 3922 & $58 \%$ & 0 & $73 \%$ & 0 & $73 \%$ \\
\hline 63045 & 3990 & $89 \%$ & 0 & $74 \%$ & 0 & $74 \%$ \\
\hline 63561 & 4052 & $13 \%$ & 0 & $75 \%$ & 0 & $75 \%$ \\
\hline 63872 & 4081 & $63 \%$ & 0 & $75 \%$ & 0 & $75 \%$ \\
\hline 64790 & 4136 & $100 \%$ & 0 & $76 \%$ & 0 & $76 \%$ \\
\hline 65363 & 4182 & $16 \%$ & 0 & $77 \%$ & 0 & $77 \%$ \\
\hline 65669 & 4196 & $32 \%$ & 0 & $77 \%$ & 0 & $77 \%$ \\
\hline 71006 & 4481 & $32 \%$ & 0 & $83 \%$ & 0 & $83 \%$ \\
\hline
\end{tabular}


$r$, Stalin's son put his entire body. And the scales did not ch she requested that her dead body be cremated and its ashe her. But he could not move his body. His head, perhaps? No, his muzzle. Without moving his body, the dog took the end of ed to see her soul through her body. Adam was like Karenin. , skillfully tying them to his body with a long ribbon. She w nothing about the duality of body and soul and had no conc e stretched one arm across his body and closed her eyes. The wn, and because it set her own body ever so slightly in moti him, raining down on his naked body. Then she went into the elf on him, cover him with her body, when suddenly she notic noticed something strange: his body was quickly shrinking be stock still. The more Tomas's body shrank, the less it rese and she could press it to her body. She burst into tears of Tomas knows the insides of the body better than the insides

WordSmith Tools -- 23/3/2015

Concordance Set Tag Word \# Sent. \# Sent. Pos. ost ordinary of bodies (as the soul had regarded it until th e light of the incredible, the soul for the first time saw $t$ was completely naked. When her soul saw her naked body in th e most extraordinary body. The soul could not tear its eyes nd went into the anteroom. The soul trembled in her body, he arged end of a sewer pipe. Her soul had lost its onlooker? $r$ allow her body, on which her soul had left its mark, to ta resisted nor assisted him, her soul thereby announcing that and she realized that she (her soul) was not at all involved o stay on with Tomas only as a soul and send her body into $t$ her will. In other words, her soul did condone the proceedi body was betraying it, and the soul was looking on. Then he uld subside. For what made the soul so excited was that the xcitement was to continue, her soul $>$ s approval would have to assion and sinks deep into her soul. He leaps out of the win entire country penetrated the soul to the body, shat-tering could be more innocent, in his soul and conscience, than Oed o point-blank denied animals a soul. Man is master and propr about the duality of body and soul and had no concept of di

$\begin{array}{llllllll}72064 & 4537 & 100 \% & 0 & 85 \% & 0 & 85 \% \\ 73150 & 4615 & 65 \% & 0 & 86 \% & 0 & 86 \% \\ 73846 & 4673 & 100 \% & 0 & 87 \% & 0 & 87 \% \\ 77954 & 4924 & 24 \% & 0 & 92 \% & 0 & 92 \% \\ 79380 & 5032 & 100 \% & 0 & 93 \% & 0 & 93 \% \\ 79591 & 5043 & 89 \% & 0 & 93 \% & 0 & 93 \% \\ 79650 & 5047 & 53 \% & 0 & 93 \% & 0 & 93 \% \\ 81080 & 5135 & 67 \% & 0 & 95 \% & 0 & 95 \% \\ 81577 & 5182 & 55 \% & 0 & 96 \% & 0 & 96 \% \\ 81759 & 5195 & 100 \% & 0 & 96 \% & 0 & 96 \% \\ 82491 & 5248 & 53 \% & 0 & 97 \% & 0 & 97 \% \\ 82499 & 5248 & 80 \% & 0 & 97 \% & 0 & 97 \% \\ 82520 & 5250 & 19 \% & 0 & 97 \% & 0 & 97 \% \\ 82667 & 5259 & 100 \% & 0 & 97 \% & 0 & 97 \% \\ 83635 & 5340 & 40 \% & 0 & 98 \% & 0 & 98 \%\end{array}$

\section{Appendix (B)}

Concord List of Soul
$87 \%$

$92 \%$

$93 \%$

$93 \%$

(9)

$96 \%$

$97 \%$

$98 \%$
Head. \# Head. Pos.

$52 \% \quad 0$

$40,6632,547$

$40,616 \quad 2,546$

$40,580 \quad 2,545$

$40,676 \quad 2,548$

$41,153 \quad 2,568$

$41,108 \quad 2,566$

$40,740 \quad 2,550$

$40,423 \quad 2,535$

$40,350 \quad 2,530$

$36,380 \quad 2,232$

$40,488 \quad 2,540$

$40,563 \quad 2,543$

$40,544 \quad 2,543$

$40,509 \quad 2,54$

$64,932 \quad 4,148$

$61,806 \quad 3,914$

$58,406 \quad 3,695$

$76,788 \quad 4,850$

$79,652 \quad 5,047$

\section{$20 \%$}

$13 \%$

$14 \%$

$27 \%$

$9 \%$

$50 \%$

$36 \%$

$59 \%$

$56 \%$

$50 \% \quad 0$

$89 \% \quad 0$

$21 \% \quad 0$

$73 \% \quad 0$

$100 \% \quad 0$

$77 \% \quad 0$

$71 \% \quad 0$

$100 \% \quad 0$

$65 \% \quad 0$ 
$41,211 \quad 2,571$ her in a soft, deep voice, her soul would take courage and e calling forth her terri-fied soul; the man cannot resist $t$ was what finally re-stored her soul's sight. During her next ime she screamed less, but her soul was still blinded by lov cannot resist the woman whose soul thus responds to his voi completely unlike Tereza, her soul inside her would be the

. It was not an easy task: her soul her sad, timid, self-eff face reflected the crew of the soul charging up from below. as a time of intoxication: her soul would rise to the surfac

her sad, timid, self-effacing soul lay concealed in the dep t next to him. (The crew other soul rushed up to the deck ot ind voice, and Tereza felt her soul rushing up to the surfac the beers on the tray, and her soul lay somewhere at the lev ad been accounted for, was the soul. Today, of course, the $b$ concilable duality of body and soul, that fundamental human $\mathrm{r}$ of having returned. PART TWO Soul and Body 1 It would be $\mathrm{s}$ . He has also learned that the soul is nothing more than the nisms; she thought she saw her soul shining through the feat ble, and the unity of body and soul, that lyrical illusion o n. The old duality of body and soul has become shrouded in $\mathrm{s}$ was therefore a body without a soul. It was like a newborn a aying goes, are windows to the soul. Franz's body, which thr ng in the student brigade, her soul poisoned by the cheerful and one in America. PART FOUR Soul and Body 1 When Tereza her soul. But what a monstrous soul it would have to be if $i$ $\mathrm{g}$ her body as a poster for her soul. But what a monstrous so ng to peer through it into her soul, as Tereza had done sinc once coaxed forth her timorous soul from its hiding place in banish the duality of body and soul, banish perhaps even tim look in the mirror and beg her soul not to abandon the deck thrown off the ballast of the soul that laughable conceit, or of his body and allowed his soul to step out into the wor ady to dismiss the crew of her soul from the deck of her bod mons to re-nounce her fate and soul. The solidarity of the s

$\begin{array}{llll}42,191 & 2,639 & 94 \% & 0\end{array}$

$42,167 \quad 2,638 \quad 53 \% \quad 0$

$41,988 \quad 2,625 \quad 86 \% \quad 0$

$36,162 \quad 2,216 \quad 36 \% \quad 0$

$11,027 \quad 668 \quad 35 \% \quad 0$

$11,015 \quad 667 \quad 87 \% \quad 0$

$10,031 \quad 615 \quad 27 \% \quad 0$

$11,031 \quad 668 \quad 50 \% \quad 0$

$12,051 \quad 734 \quad 42 \% \quad 0$

$11,375 \quad 689 \quad 47 \% \quad 0$

$11,078 \quad 670$

$9,701 \quad 600$

$9,624 \quad 597$

$9,444 \quad 585$

$9,788 \quad 604$

$9,939 \quad 611$

$9,845 \quad 606$

$9,807 \quad 605$

$30,380 \quad 1,854$

$30,361 \quad 1,853$

$28,395 \quad 1,721$

$33,866 \quad 2,094$

$35,820 \quad 2,196$

$35,815 \quad 2,195$

$35,791 \quad 2,194$

$13,367 \quad 804$

$13,094 \quad 788$

$12,631 \quad 758$

$13,900 \quad 833$

$23,247 \quad 1,402$

$14,637 \quad 881$

$14,603 \quad 878$ 
WordSmith Tools -- 23/3/2015

N Concordance Set Tag Word \# Sent. \# Sent. Pos. Para. \#

1 Her drama was a drama not of heaviness but of lightness. W

2 s, we tend to use metaphors of heaviness. We say that someth

3 eir splendid lightness. But is heaviness truly deplorable an
Appendix (C)

Concord List of Heaviness

\begin{tabular}{llllllll} 
Para. Pos. & \multicolumn{1}{l}{ Head. \# } & Head. Pos. & Sect. \# & Sect. Pos. & File & $\%$ \\
32,223 & 1,979 & $75 \%$ & 0 & $38 \%$ & & 0 & $38 \%$ \\
32,154 & 1,970 & $100 \%$ & 0 & $38 \%$ & & 0 & $38 \%$ \\
498 & 22 & $44 \%$ & 0 & $1 \%$ & & 0 & $1 \%$
\end{tabular}

WordSmith Tools -- 23/3/2015

Appendix (C)

Concord List of Lightness

N Concordance Set Tag Word\# Sent. \# Sent. Pos. Para. \# Para. Pos. Head. \# Head. Pos. Sect. \# Sect. Pos.

1 How she wished she could learn lightness! She yearned for so

2 erious, she deprived it of its lightness, and it became forc

3 ging to betray. The unbearable lightness of being was that $t$

4 agedy, and failed to grasp the lightness and amusing insigni

5 ke its way into the unbearable lightness of being. Though to

6 anted to die under the sign of lightness. She would be light

7 her, blue, the last. PART FIVE Lightness and Weight 1 When T

8 he air, lifted by the infinite lightness of a world that has

9 the burden but the unbearable lightness of being. Until tha

10 hen shall we choose? Weight or lightness? Parmenides posed t

11 ht-ness? Parmenides responded: lightness is positive, weight

12 ainst it in all their splendid lightness. But is heaviness $t$

13 heaviness truly deplorable and lightness splendid? The heavi

14 and Sunday, he felt the sweet lightness of being rise up to

15 drama not of heaviness but of lightness. What fell to her 1

16 on. The only certainty is: the lightness/weight opposition i

17 ld: he was enjoy-ing the sweet lightness of being. (Did he f

$\begin{array}{llll}37,307 & 2,286 & 100 \% & 0 \\ 37,368 & 2,289 & 70 \% & 0 \\ 32,386 & 1,993 & 44 \% & 0 \\ 37,294 & 2,285 & 82 \% & 0 \\ 68,709 & 4,347 & 95 \% & 0 \\ 73,178 & 4,617 & 100 \% & 0 \\ 45,196 & 2,865 & 10 \% & 0 \\ 65,691 & 4,196 & 82 \% & 0 \\ 32,239 & 1,980 & 88 \% & 0 \\ 620 & 29 & 100 \% & 0 \\ 685 & 34 & 50 \% & 0 \\ 495 & 21 & 100 \% & 0 \\ 502 & 22 & 89 \% & 0 \\ 8,205 & 510 & 43 \% & 0 \\ 32,226 & 1,979 & 100 \% & 0 \\ 703 & 37 & 44 \% & 0 \\ 7,965 & 494 & 87 \% & 0\end{array}$

$\begin{array}{lll}\text { File } & & \\ 44 \% & 0 & 44 \% \\ 44 \% & 0 & 44 \% \\ 38 \% & 0 & 38 \% \\ 44 \% & 0 & 44 \% \\ 81 \% & 0 & 81 \% \\ 86 \% & 0 & 86 \% \\ 53 \% & 0 & 53 \% \\ 77 \% & 0 & 77 \% \\ 38 \% & 0 & 38 \% \\ 1 \% & 0 & 1 \% \\ 1 \% & 0 & 1 \% \\ 1 \% & 0 & 1 \% \\ 1 \% & 0 & 1 \% \\ 10 \% & 0 & 10 \% \\ 38 \% & 0 & 38 \% \\ 1 \% & 0 & 1 \% \\ 9 \% & 0 & 9 \%\end{array}$

